\title{
Developing a Framework for Designing the Instructional Computer Games in Cognitive Domain at Micro Level and Studying Its Effectiveness in principles learning
}

\author{
Hossein Dehghanzadeh \\ PH-D student of instructional Technology, Allameh Tabataba'i University, Tehran. Iran \\ Email: hossein.dehganzadeh@gmail.com \\ Osameh Salimi \\ Master of Educational Psychology at Allameh Tabataba'i University, Tehran, Iran \\ Hojjat Dehghanzadeh
}

PH-D student of instructional Technology, Tarbiat Modarres University, Tehran. Iran

Zohreh Azizi

Master of Clinical psychology, Islamic Azad University, Varamin

\section{Doi:10.5901/mjss.2016.v7n3p411}

\section{Abstract}

\begin{abstract}
The aim of this research was to develop instructional game design framework for types of cognitive domain subjects in micro level and evaluation of its effectiveness in principles learning. To achieve this goal mixed method research used. To obtain the framework and its evaluation, In the qualitative method inductive analysis and in the quantitative, survey method have been used. Also for extrinsic evaluation of the framework in principles learning, experimental research with control group have been used. From qualitative analysis about computer games mechanic, 31 game mechanics extracted.. To intrinsic evaluation of Proposed framework, this framework with its explaining appendix have been send for 25 instructional and digital game specialists. The results of evaluation showed the proposed framework for cognitive domain subjects have appropriate authenticity. Also to extrinsic or effectiveness evaluation, proposed framework experimented on 40 students in control and experimental groups with pre and posttests. Results of covariance analysis showed there is significant difference between the game has been designed on the basis of the proposed framework and existing game.
\end{abstract}

Keywords: instructional game, cognitive domain, instructional game framework

\section{Introduction}

We live in a world that constantly the new technologies emerge and create challenges for the field of educational technology, and at the same time, provide appropriate opportunities for improved learning. Present century also witnessed creation and penetration of one of the technologies which is known as "Digital Technology". This digital technology or as Connolly (2009) states, this "digital culture" has affected the ways of activities, social relations, economy, and communication, etc. of today generation. In other words, the digital culture has changed the human lifestyle in $21^{\text {st }}$ century.

Despite this fact that we have witnessed the emerging and development of new technologies and then the changing of today human being, traditional teaching methods have been maintained by educational systems and have not been changed in accordance to characteristics of modern human. In this regard, Prensky (2001) suggests that many researchers of learning and teaching fields state that if an individual of 200 years ago, who comes to the present times, will be surprised from changes which have been occurred from that time up to now except schools. However, he states that our educational system has failed and schools have actually become boring for learners. Even it is more boring than watching TV and working; and we, as educational professionals, are blamed for boringness of schools. Because for today's digital generation (Engage-me generation), our education is not only engaging but also, as Prensky argues, is boring. Human being is living in a world in which s/he has been born, and s/he performs the works and activities that are 
interesting for her/him. Today's generation was born in the digital world. In other words, today's generation has changed comparing to generation of Socrates. Their preferences and interests have changed and inevitably, in order our education is not boring for day's students we must change our teaching methods to pay attention to the interests of today's generation. To answer the question of what must we do in order our teaching is not boring for our students, Prensky (2001) states that we must change our teaching approach to a learner-based approach, and emphasizes that the gamebased learning can a good learner-based approach for today's generation. Farlane (2005) showed that games are more engaging, more enjoyable and more effective than traditional methods.

However, to apply this learning-based approach in teaching and learning, we are facing deficiency in resources in the world. Even it seems that the resources that have been written in the field of teaching and learning have not paid enough attention to the method or teaching and learning tool than game as the source. Botturi and Loh (2008), reviewing several popular books in the field of educational technology, found that few of them have introduced game as the source or teaching tool. These limited resources have considered games as motivational activities to support and complete classroom lessons. Some educators also consider the games as the competitive exercises and activities that in this viewpoint the actual potentials and activities of the games are not take into consideration. The review of this kind of books indicates that the authors have eliminated the games from the texts of educational technology and consider them against teaching, and the readers of these books also disagree to apply games in teaching and learning. Based on the above, this study can add a source to the literature of educational technology. In this regard, Lacasa et al., (2014) also states that in the present time, computer games have entered into the everyday life of children, adolescents and youth. In spite of this influence and importance, educational potentials and their capabilities in strengthening thinking have been neglected.

Also about doing research on comparing the elements of computer games and the principles of teaching and learning, Richard (2006) states that giving the practical tips on how, when, to whom and in what circumstances, computer games and teaching and learning can be synthesized to enhance the learning capacity of computer games need to be studied by researches in the fields of computer game-based learning. Also, Richard, quoting from Del Blanco, states that computer games are new media and the educators are facing different challenges in using these new media in learning and teaching, including paying attention to educational principles and matching the games with the goals of curriculum. As explained earlier, several researches have been done on the engagement and effectiveness of computer games, but enough study has not been conducted on why and how computer games have engaged the learners in learning process and have been effective in this regard, and also how we can integrate and mix them with teaching and learning. In this regard, Chandler (2013) also states that many studies have been done in the field of educational computer games. Most of the research focuses on what players learn from these games, but we are facing the deficiency of research about how teachers can integrate and mix these principles of learning and teaching to improve learning in computer games.

\section{Literature Review}

One of the cases that we can answer the question "How can we design appropriate educational game?" is that we should use the educational design patterns, because these patterns show the structured method or map for designing and producing computer games (Kelli, 2013).

To this end, numerous researches have been conducted and several models have been presented. One of these known models is DODDEL ${ }^{1}$ which was designed and developed by Mahon at Edith Cowen University of Australia. This model is a design pattern with a systemic approach. Situation analysis (objectives and outcomes, learning approach, learner and context), design (intended concepts, challenges, feedbacks and game approach), product design (organizing concepts, game behavior and activity), product document (general document, certain documents and variable documents), prototype product, final product, implementation and achievement and final assessment are key elements of the model (Norouzi and Dehghanzadeh, 2012). GOM ${ }^{2}$ is another model which the game situation, visual space and the issues and challenges are the major elements forming it. Kiili also proposed "experimental gaming model" in 2005. The schema elements of this model included learning objectives, challenges, fluency, idea generation, active experience, feedback, and reflective observation. This model shows the active learning process in computer games by posing the features of computer games.

The model is not appropriate for designing at the micro level. In fact, it can be said that none of these teaching models has been designed at the micro level. This case is exactly the main problem of the present study. In other words, the main problem of the present study is the absence of an appropriate model or framework to apply the computer games in educational designing in the cognitive domain at the micro level. The present study is seeking to develop a framework

\footnotetext{
1 document-oriented design and development for experimental learning

2 Game object model
} 
for designing educational computer games to teach a variety of cognitive domain contents, including facts, concepts, principles and procedures at micro level. This framework introduces a method for combination and integration of computer games in teaching and learning at cognitive domain for learning designers and developers of computer games. According to the abovementioned cases, we are faced with the following question: How we can teach the cognitive objects of fact types at the micro level through computer games? To answer this question, we are faced with some other questions. What elements have the computer games through which we are able to provide the teaching? Through what elements of computer games and how can we teach "facts"? Through what elements of computer games and how can we teach "concepts"? Through what elements of computer games and how can we teach "procedure"? Through what elements of computer games and how can we teach "principles "?

\section{Research Objectives}

The main objective of this research was to develop instructional game design framework for types of cognitive domain subjects in micro level and evaluation of its effectiveness in principles learning. To achieve this main objective, the following objectives were determined.

1) Identifying the mechanics of computer games.

2) Identifying proper mechanics to learn the subjects of fact type.

3) Identifying proper mechanics to learn the subjects of concepts type.

4) Identifying proper mechanics to learn the subjects of procedure type.

5) Identifying proper mechanics to learn the subjects of principles type.

6) Surveying effectiveness of the proposed mechanics to design educational computer games to learn the principles.

\section{Research Method}

This research was conducted through mixed method research. Among the qualitative research methods, the qualitative content analysis was used. Reason of choosing this method is the obtaining the intended framework from content analysis. To do qualitative content analysis in the study, written sources (books, articles, thesis and other writings on the subject of this paper) were used.

Quantitative method selected for validating and evaluation effectiveness of the proposed framework. From quantitative aspect of the research, after preparing the model using qualitative methods, first, its internal validation was done using the ideas of 25 professionals of training and videogames, and then it was implemented experimentally at the two experimental and control groups, and its external validation was done. For external validation, pretest-posttest with control group design was used. After the pre-test was performed by using researcher-made questionnaire, the model was used in the experimental group, while the control group received conventional teaching method.

\section{Methods and Tools for Collecting Data}

In this study, several methods have been used for collecting data, which include the following:

A) Qualitative content analysis of written documents

1) Articles: To find related articles, first the key words related to the content analysis were identified, and then these keywords were searched. Article selection criterion was the existence of one of these keywords in the title of the paper. Due to the large number of articles, the priority was given to those that were indexed from 1990 onwards.

2) Books: Also by searching the above keywords in databases in which e-books can be downloaded, 26 books on the subject were obtained. Book selection criterion was the special focus on "computer gamebased learning". For this purpose, the list of books was carefully examined. With this restriction, 10 book chapters related to computer game elements were analyzed.

B) Measurement: The researcher-made questionnaire validated for internal validity of the model by experts and researcher-made questionnaire for learning games for external validation of the obtained model were used.

\subsection{Data collection Instrument}

In this study, the following tools were used to collect data: 
The validating questionnaire of proposed framework: After identifying the elements of digital games, game mechanics and learning methods of cognitive issues (facts, concepts, procedures and principles) and preliminary design of the proposed framework, questions related to internal evaluation of the model was developed considering the experts' ideas. The validity of this tool was done using the experts' ideas and the reliability of this instrument was also done in a pilot study by 15 experts in educational technology and digital games, which was calculated equal to 0.78 through Cronbach's alpha for the conceptual model.

B) To validate the obtained model in practice, the questionnaire of effectiveness rate of designed game was developed in accordance with the framework of this research. The content validity of the questionnaire was validated by experts and its reliability was obtained equal to 0.88 using Cronbach's alpha.

\subsection{Participants}

In this study, the statistical population was significant from two aspects: (1) in the qualitative research method of inductive content analysis type, the statistical population consists of all related resources and scientific articles indexed in databases of Proquest, Springer, Science Direct, Emerald, Ebsco, and Sage, which have been used in this study. Sampling was purposive sampling from the population, which follows from the principle of gradual choice to reach the saturation. (2) In quantitative method of survey type, the population consisted of all teachers in the field of educational technology, doctoral students of educational technology and instructors of designing computer games who had works in their own special fields. Of this population, 25 individuals were purposively selected as sample size. In the experimental method, the population of this study consisted of all male students in the sixth grade in the city of Tabriz, who had enrolled in the academic year 2015-2016. The sample size consisted of 40 students who were selected through purposive sampling method, and the intended framework was performed on the sample in English language course. Researcher used the purposive sampling method because of restriction in choosing schools that were equipped to computers with capability of performing the intended games produced.

In the quantitative method in the intended survey, descriptive statistics were used to summarize data. To analyze the data obtained from the implementation of the model, corresponding to the project, analysis of covariance was used.

\subsection{Results}

\subsubsection{What are the mechanics of computer games?}

Digital games have so many diverse elements. Some of these elements that are related to the activities and interactions of players in the game is called mechanics, such as driving in racing games, creating in the simulation games, shooting in the action games, matching puzzle games. Mechanics also have various types and roles, but in this research the mechanics have been posed that are important and highlighted in types or styles of games; in other words, the most important and applicable activities that the players performs in the games have been presented in this study. Because each game has its own mechanics and the mechanics of each game determine the type of activities the players do in that game. Therefore, the mechanics of the game were extracted and selected among the diverse elements of digital games to match the variety of topics with the diverse mechanics in accordance of the characteristics of the mechanics and activities of the players. The obtained mechanics based on qualitative content analysis are presented in the table below.

Table 2-4. The mechanics of digital games

\begin{tabular}{|l|l|l|}
\hline 1 & Problem solving & $\begin{array}{l}\text { Thomas_Connolly(2009), nicola witton(2010),Kapp(2012), Brien(2010), Becker(2006), Garris at all } \\
\text { (2002), Adams, Joris(2012), Hung(2010), prensky(2001), }\end{array}$ \\
\hline 2 & Practice/real action & $\begin{array}{l}\text { Connolly(2009), witton(2010),Kapp(2012), Brien(2010), Becker(2006), Garris at all (2002), Adams, } \\
\text { Joris(2012), Jason Fritts(2009), de Freitas(2011). }\end{array}$ \\
\hline 3 & design & witton(2010),Kapp(2012), Adams, Joris(2012), Jason Fritts(2009), de Freitas(2011). \\
\hline 4 & jumping & Hung(2010) \\
\hline 5 & Puzzle solving & $\begin{array}{l}\text { Connolly(2009), Hung(2010), witton(2010),Kapp(2012), Adams, Joris(2012), Jason Fritts(2009), } \\
\text { Freitas(2011), prensky(2001). Van eck(2010). }\end{array}$ \\
\hline 6 & story & $\begin{array}{l}\text { Brien(2010), Connolly(2009), Hung(2010), witton(2010),Kapp(2012), Adams, Joris(2012), Jason } \\
\text { Fritts(2009), de Freitas(2011),prensky(2001). Van eck(2010). }\end{array}$ \\
\hline 7 & Decision making & $\begin{array}{l}\text { Brien(2010, , witton(2010),Kapp(2012), Adams, Joris(2012), Jason Fritts(2009), de Freitas(2011), } \\
\text { Van eck(2010). }\end{array}$ \\
\hline
\end{tabular}




\begin{tabular}{|c|c|c|}
\hline 8 & sorting & Kapp(2012) \\
\hline 9 & Move Pieces & Hung(2010) \\
\hline 10 & Response speed & Hung(2010), Adams, Joris(2012), Jason Fritts(2009). \\
\hline 11 & run & Hung(2010) \\
\hline 12 & collect & Adams, Joris(2012), de Freitas(2011),Hung(2010), ), Jason Fritts(2009). \\
\hline 13 & Social interaction & $\begin{array}{l}\text { Connolly(2009), nicola witton(2010),Kapp(2012), Brien(2010), Becker(2006), Garris at all (2002), } \\
\text { Adams, Joris(2012), Hung(2010), prensky(2001),Hirumi(2015). }\end{array}$ \\
\hline 14 & Real situation & $\begin{array}{l}\text { witton(2010),Kapp(2012), Brien(2010), Becker(2006), Garris at all (2002), Adams, Joris(2012), } \\
\text { Hung(2010). }\end{array}$ \\
\hline 15 & $\begin{array}{l}\text { Implementation and } \\
\text { operation }\end{array}$ & $\begin{array}{l}\text { witton(2010),Kapp(2012), Brien(2010), Becker(2006), Hung(2010), de Freitas(2011), Jason } \\
\text { Fritts(2009). }\end{array}$ \\
\hline 16 & matching & Djaouti at all(2008),Kapp(2012), Hung(2010) \\
\hline 17 & moving & Djaouti(2008), Hirumi(2015). \\
\hline 18 & $\begin{array}{l}\text { Hierarchy/step to } \\
\text { step }\end{array}$ & witton(2010) \\
\hline 19 & Arrange/pick up & Kapp(2012) \\
\hline 20 & Practice with tools & witton(2010), Brien(2010), Becker(2006), Jason Fritts(2009), Adams, Joris(2012). \\
\hline 21 & Exploration & $\begin{array}{l}\text { Brien(2010), Becker(2006), Jason Fritts(2009), Adams, Joris(2012), Kapp(2012), Hung(2010), } \\
\text { Hirumi(2015). }\end{array}$ \\
\hline 22 & Manipulation & Becker(2006) \\
\hline 23 & Experience of role & Brien(2010), Jason Fritts(2009), Adams, Joris(2012), Kapp(2012), \\
\hline 24 & combat & Freitas(2011),Brien(2010), Jason Fritts(2009), Adams, Joris(2012), Kapp(2012), \\
\hline 25 & construct & $\begin{array}{l}\text { Brien(2010), Connolly(2009), witton(2010),Kapp(2012),Becker(2006), Garris at all (2002), Adams, } \\
\text { Joris(2012), Hung(2010),Hirumi(2015). }\end{array}$ \\
\hline 26 & Test and retest & witton(2010), Hung(2010). \\
\hline 27 & $\begin{array}{l}\text { resource } \\
\text { management }\end{array}$ & $\begin{array}{l}\text { Brien(2010), Connolly(2009), witton(2010),Kapp(2012),Becker(2006), Adams, Joris(2012), } \\
\text { Hung(2010), Jason Fritts(2009), Freitas(2011). }\end{array}$ \\
\hline 28 & Remove and destroy & Jason Fritts(2009), Freitas(2011), Kapp(2012), Adams, Joris(2012) \\
\hline 29 & Aim and shooting & Freitas(2011), Kapp(2012), Adams, Joris(2012),Hung(2010). \\
\hline 30 & repeat & Kapp(2012), Connolly(2009), witton(2010), \\
\hline 31 & Drag and drop & Kapp(2012) \\
\hline
\end{tabular}

Feritts (2009), on classification of certain styles of digital games and their certain mechanics, writs that exploration, solving puzzles, adding up the items are the strong stories special for adventure game style. Mechanics of velocity, realtime, targeting and firing, remove and destroy are specific for action style. Role-play style also includes its own mechanics, including role play, challenge, fight, skill and fantasy. Simulation style covers its particular mechanics of actual situation, working with tools (tools such as tanks, planes, etc.), building (like building a house, etc.). Mechanics of resource management, competition, decision making and time management are considered as the important strategic style mechanics. Kapp (2012) states that, the important mechanics of educational digital games include mechanics of the story, matching and comparing, searching and coining a word, repetition, grouping, and dragging and dropping, experiencing a concept or experiencing a role. Ernest Adams and Joris (2012) have also divided the mechanics of the games as physical mechanics (such as motion and pushing, driving the objects), economic mechanics (e.g., adding up, producing, trading), progressive mechanics (such as strengthening avatar, enlarging, completing the process), tactical mechanics (such as attack or defense, movement of parts, management of resources and time) and social mechanics (in pair games or more than two). Freitas (2011) also argues that adding, deleting, defending, eluding, resource management, competition, and creation are the most important mechanics of digital games. Also Jauoti (2008) also considers the important mechanics of educational digital games as eluding, management, conflict, incident or chance, shooting, building or creating, destroying, aligning, writing, moving and selecting. Hirumi (2015) states that, the important matching-style mechanics of educational digital games include the construction, searching and exploration, driving, selection, challenge, control, simulation, rewarding. 
4.3.2 By which mechanics, the various types of cognitive subjects can be thought in computer games?

Table 3. Proper mechanics to learn the subjects of fact type

\begin{tabular}{|l|c|c|c|c|c|c|}
\hline Mech\$anics & $\mathbf{N}$ & Minmum & Maximum & Sum & Mean & Std.Deviation \\
\hline puzzle & 21 & 1.00 & 5.00 & 89.00 & 4.23 & $0 / 94365$ \\
\hline repeat & 21 & 4.00 & 5.00 & 104.00 & 4.95 & $0 / 21822$ \\
\hline Move Pieces & 21 & 2.00 & 5.00 & 69.00 & 3.28 & $0 / 95618$ \\
\hline Drag and drop & 21 & 3.00 & 5.00 & 93.00 & 4.42 & $0 / 59761$ \\
\hline Remove/destroy & 21 & 1.00 & 5.00 & 61.00 & 2.90 & 1.30018 \\
\hline Aim and shooting & 21 & 1.00 & 5.00 & 90.00 & 4.28 & 1.05560 \\
\hline story & 21 & 3.00 & 5.00 & 95.00 & 4.52 & $0 / 67964$ \\
\hline
\end{tabular}

Table 4. Proper mechanics to learn the subjects of concept type

\begin{tabular}{|l|c|c|c|c|c|c|}
\hline Mechanics & $\mathrm{N}$ & Minmum & Maximum & Sum & Mean & Std.Deviation \\
\hline matching & 21 & 3.00 & 5.00 & 90.00 & 4.28 &.$/ 64365$ \\
\hline Arrange/pick up & 21 & 3.00 & 5.00 & 85.00 & 4.04 &.$/ 80475$ \\
\hline sorting & 21 & 4.00 & 5.00 & 102.00 & 4.85 &.$/ 35857$ \\
\hline Role Experience & 21 & 1.00 & 5.00 & 73.00 & 3.47 & $1 / 16701$ \\
\hline exploration & 21 & 3.00 & 5.00 & 81.00 & 3.85 &.$/ 72703$ \\
\hline collect & 21 & 4.00 & 5.00 & 91.00 & 4.33 &.$/ 48305$ \\
\hline
\end{tabular}

Table 5. Proper mechanics to learn the subjects of procedure type

\begin{tabular}{|l|c|c|c|c|c|c|}
\hline Mechanics & $\mathrm{N}$ & Minimum & Maximum & Sum & Mean & Std.Deviation \\
\hline Problem solving & 21 & 2.00 & 5.00 & 87.00 & 3.95 & 1.04550 \\
\hline exploration & 21 & 1.00 & 5.00 & 68.00 & 3.09 & 1.22384 \\
\hline Implementation and operation & 21 & 3.00 & 5.00 & 104.00 & 4.72 & .55048 \\
\hline Decision making & 21 & 1.00 & 5.00 & 53.00 & 2.40 & 1.45346 \\
\hline Hierarchy/Limited time & 21 & 3.00 & 5.00 & 92.00 & 4.18 & .88884 \\
\hline
\end{tabular}

Table 6. Proper mechanics to learn the subjects of principles

\begin{tabular}{|l|c|c|c|c|c|c|}
\hline Mechanics & $\mathrm{N}$ & Minimum & Maximum & Sum & Mean & Std.Deviation \\
\hline Problem solving & 21 & 3.00 & 5.00 & 78.00 & 3.71 &.$/ 78376$ \\
\hline Decision making & 21 & 3.00 & 5.00 & 80.00 & 3.80 &.$/ 74960$ \\
\hline Implementation and operation & 21 & 4.00 & 5.00 & 98.00 & 4.66 &.$/ 48305$ \\
\hline construct & 21 & 4.00 & 5.00 & 98.00 & 4.66 &.$/ 48305$ \\
\hline managment & 21 & 3.00 & 5.00 & 74.00 & 3.52 &.$/ 67964$ \\
\hline Test and retest & 21 & 4.00 & 5.00 & 95.00 & 4.52 &.$/ 51177$ \\
\hline design & 21 & 2.00 & 5.00 & 79.00 & 3.76 &.$/ 94365$ \\
\hline Manipulation & 21 & 3.00 & 5.00 & 90.00 & 4.28 &.$/ 56061$ \\
\hline
\end{tabular}

The proposed framework in the present study for teaching the cognitive subjects through digital games

\begin{tabular}{|c|c|c|c|c|c|c|c|c|}
\hline Genre & Mechanic & & & & & & & subjects \\
\hline $\begin{array}{l}\text { Puzzle } \\
\text { Quiz game } \\
\text { Action/Arcade Adventure }\end{array}$ & & $\begin{array}{l}\text { Aim and } \\
\text { shooting }\end{array}$ & $\begin{array}{l}\text { Removel } \\
\text { destroy }\end{array}$ & Drag and drop & Move Pieces & repeat & puzzle & facts \\
\hline $\begin{array}{l}\text { Role-playing } \\
\text { Action } \\
\text { Simulation }\end{array}$ & & collect & exploration & $\begin{array}{l}\text { Role } \\
\text { Experience }\end{array}$ & sorting & $\begin{array}{l}\text { Arrange } \\
\text { /pick up }\end{array}$ & matching & concepts \\
\hline $\begin{array}{l}\text { Timed games, reflex } \\
\text { games Adventure }\end{array}$ & & & $\begin{array}{l}\text { Hierarchyl } \\
\text { Limited time }\end{array}$ & $\begin{array}{l}\text { Decision } \\
\text { making }\end{array}$ & $\begin{array}{l}\text { Implementation } \\
\text { and operation }\end{array}$ & Exploration & $\begin{array}{l}\text { Problem } \\
\text { solving }\end{array}$ & procedure \\
\hline Simulation Strategy & $\begin{array}{l}\text { Test and } \\
\text { retest }\end{array}$ & design & managment & construct & $\begin{array}{l}\text { Implementation } \\
\text { and operation }\end{array}$ & \begin{tabular}{|l} 
Decision \\
making
\end{tabular} & $\begin{array}{l}\begin{array}{l}\text { Problem } \\
\text { solving }\end{array} \\
\end{array}$ & principles \\
\hline
\end{tabular}


After extracting mechanics and matching the types of them with a variety of issues, experts of educational technology and computer games evaluated their fitness with teaching of the various types of cognitive subject (facts, concepts, procedure and principles). As the above tables show, according to content analysis and assessments done by specialists, puzzle mechanics, repetition, movement of parts, drag and drop, removing and destroying, targeting and shooting and story are appropriate mechanics to learn facts; matching, picking , classification, role play, search and exploration, adding up are proper mechanics to learn the concepts; problem solving, search and exploration, acting, performing, decision-making and hierarchy or time limit are appropriate mechanics of learning issues of procedure type; problem solving, decision making, implementing, creating, managing, testing and retesting, designing, manipulating are proper mechanics to learn the subjects of principle types in digital games. The appropriateness of the obtained mechanics with the styles of digital games was determined by interviewing with eight experts of computer games. In other words, through an interview it was determined which mechanics are executable and practical in which genre of computer games. This appropriateness is presented in the proposed framework.

\subsubsection{To what extent is effective the proposed mechanics to design educational computer games to learn the principles?}

Hypothesis: The learning rate of students who learn through the proposed mechanics is higher than the learning rate of students who learn through the conventional games.

The results of the analysis of covariance for learning scores after adjusting the pretest

Tests of Between-Subjects Effects

\begin{tabular}{|l|c|c|c|c|c|}
\hline Source & Type III Sum of Squares & $\mathrm{df}$ & Mean Square & $\mathrm{F}$ & Sig. \\
\hline Corrected Model & $89.724^{\mathrm{a}}$ & 2 & 44.862 & 7.719 & .002 \\
Intercept & 331.833 & 1 & 331.833 & 57.093 & .000 \\
pre & 8.499 & 1 & 8.499 & 1.462 & .234 \\
group & 85.941 & 1 & 85.941 & 14.786 & .000 \\
Error & 215.051 & 37 & 5.812 & & \\
Total & 8229.000 & 40 & & & \\
Corrected Total & 304.775 & 39 & & & \\
\hline
\end{tabular}

The results of the analysis of covariance for evaluating the differences of groups in learning scores were presented in the above table. According to the obtained results from the table $(P<0.05 ; d f=1 ; F=11.579)$, when the pretest effect is eliminated from learning outcomes, the difference between the training groups for ordinary and designed games with research model is significant at the level of $95 \%$. Therefore, there is a significant difference between the scores of the groups in learning tests. Accordingly it can be concluded that the two mentioned games have different effects on student learning.

\section{Discussion and Conclusion}

According to the results obtained from various studies, today's digital generation prefers to engage the certain media of their own time. According to Monroe (2015), the educational value of digital games is undeniable. Also, Alle et al. (2016) and Clark et al. (2015) suggest that the analysis and meta-analysis have shown that digital game-based learning is effective. Butler (2015) in an article entitled "The use of computer games as foreign language learning tasks for digital natives" suggests that for being effective the digital games in learning, it is very important to determine which features of digital games are suitable for educational purposes. In recent years, researchers seek to design and produce digital games that are both educationally effective and engage learners in the learning process. In this study, researcher sought to provide a framework that in the case of implementation, the computer games can be effective in terms of education and also engage the learners in the learning process. For this purpose, in accordance to the obtained framework, in designing the intended games the features or mechanics of comparing, classification, role play, searching and exploration, and adding-up have been used.

Hiromi and Stapleton (2008) consider the educational activities and learning for subjects of concept types in using of the presentation of the important features of concepts, examples, etc., and the use of conceptualized maps to show the relationship of concept with types and elements of concepts for using the pictures in learning. Merrill (1983) also believes that in learning the concepts, the learners should be able to detect examples from other examples and classify them. Kapp (2012) states that learners, to learn concepts, should know the important features of concepts to be able to 
recognize the examples from other examples of concepts and classify them. He suggests that to learn the concepts in digital games, it is better to use the mechanics of matching, classifying, and experiencing the concept. Van Eck (2010) also states that in digital games the strategic styles, simulation and role-play are appropriate to teach and learn the concepts and principles and role play, story, adding up, the actual situation, picking and management are the important mechanics of this style. So as Butler (2015) and others, it can be said with certainty that in order the digital games to be effective in learning it is much important to determine which features and elements of digital games are suitable for a variety of educational purposes.

In learning the facts, the learning activities of repetition and practice, association and relationship, expanding and development, and classification and grouping can be used. Hiromi and Stapleton (2008) know the teaching and teaching activities for issues of fact types as mnemonic tools (keyword, mental imagery, acronym), practice and repetition, classifying in different categories, using concept maps to show the relationship between facts, using tables, graphs and images, using the relationship between facts. Prensky (2005) in "learning based on digital games" states that to teach facts, learning activities of memorization, practice and repetition, association and relationship, and questions are more appropriate, and to implement these activities in the digital gaming, the game styles of flashcard type, puzzles and puzzle and memory are suitable.

Nicola Witton (2010) in "learning with digital games" suggests that the styles of puzzle games are more suitable for learning and remembering subjects of the fact types. Thomas Connolly (2009) states that quiz games that are a kind of puzzle games are more ideal for teaching and learning facts. Kapp (2012) states that in teaching facts, the mechanics of drag and drop, repetition, story, comparing, questions-based mechanics, and exploration and search are used. Wilson et al. (2009) in an article entitled "comparison between the elements of digital games and learning objectives" explain that the puzzle games are suitable for learning the describing knowledge and facts. Also, Muzi-Lane (2010) in an article entitled "designing effective learning games" states that designing quiz and memory games is easier and more appropriate for teaching subjects of fact types.

According to important features of concepts, in learning them the learners recognize the concepts from other concepts and classify them. Hiromi and Stapleton (2008) consider the educational activities and learning for subjects of concept types in using of the presentation of the important features of concepts, examples, etc., and the use of conceptualized maps to show the relationship of concept with types and elements of concepts for using the pictures in learning. Merrill (1983) also believes that in learning the concepts, the learners should be able to detect examples from other examples and classify them. Kapup (2012) states that learners, to learn concepts, should know the important features of concepts to be able to recognize the examples from other examples of concepts and classify them. He suggests that to learn the concepts in digital games, it is better to use the mechanics of matching, classifying, and experiencing the concept. Van Eck (2010) also states that in digital games the strategic styles, simulation and role-play are appropriate to teach and learn the concepts and principles and role play, story, adding up, the actual situation, picking and management are the important mechanics of this style.

Procedures are subsequent stages that the learners learn to perform a task such as solving an account problem (kemp, 2013). In learning, the learners observe the procedures, and then practice them. In this regard, Prensky (2005) states that observation and imitation of the stages of the procedure and practice are the important activities of learning subjects of procedure type.

Van Eck (2010) also states that all types of game-plays can support all types of knowledge or provide the ground for learning all types of knowledge, but games of puzzle, action and adventure styles are more appropriate for learning descriptive knowledge and facts; games with simulation and adventure styles are suitable for learning process and procedural subjects, and strategic simulation games and role play can support the subjects of concept an principle types. On the other hand, Fritts (2009) argues that the real situation, working with tools, searching and exploration, and problem solving are important mechanics of digital games with adventure and simulation styles. Also, Van Eck (2010) states that, the main feature of the procedural subjects is that several activities or tasks should be done in a certain order successively. In digital games, performing the stages of a task is done with the stage-to-stage solving of an algorithmic problem through mechanic of element of time limit, that is, the player must do an activity at a certain and specified time limit and then after finishing the time, s/he should do the next activity or step within another specified time limit. So, the player will perform all necessary activities step by step (time limit or time mechanic) at designated times. Prensky (2001) also states that the style of games that use a time limit is very appropriate for teaching and learning procedural and process subjects.

Principle or rule is a term that first expresses the causative relationship between subjects and then between concepts. For example, the sum of the sides of a triangle is 180 degrees, or water boils at 100 degrees (kemp, 2013; kapp 2012). In digital games for teaching and learning the principles, first the player or learner receives the examples, do 
or exercise them, and explores the rule by doing exercises, that is, the rule is practiced by the learner in practice (Kapp, 2012). The basic activity of learning principles in digital games is to do the task in practice and observe the result. Also Kapp states that the most appropriate style for this activity or learning the principles and rules is the simulation style. Prensky (2005) also suggests that, learning activity for subjects of principle type is to understand the principle through doing that principle or rule by the player or learner. Van Eck (2010) also states that, the simulation style is appropriate for learning the principles. In addition, Van Eck in an article entitled "division and framework of educational digital games to improve the learning of the types of problem solving" states that the styles of strategic games and simulation are proper to teach the principles or rules. Fritts(2009) also argues that the real situation, practice with tools, building, test and retest, management and decision-making are the most important mechanics of simulation style in digital games.

\section{References}

Adams,Ernest, Joris Dormans.(2010). Game Mechanics: Advanced Game Design, Berkeley,New Riders

All ,Anissa , Elena Patricia Nu, nez Castellar, Jan Van Looy.(2016). Assessing the effectiveness of digital game-based learning:Best practices, Computers \& Education 92, 90-103

Apice,Ciro,Claudio Grieco,Rossella Picopo,Luca Liscio.(2015). Advanced learning technologies for eLearning in the enterprise: Design of an Educational Adventure Game to teach computer security,journal of visual language and computing,31,260-266

Borja Manero, Javier Torrente,Angel Serrano, Martínez-Ortiz, Baltasar Fern andez-Manj.(2015). Can educational video games increase high school students' interest in theatre?,computers and education,87,182-191

Botturi,L,Loh.C.S .(2008). Once Upon a Game: Rediscovering the Roots of Games in Education,in Christopher Thomas Miller(Eds): Games: Purpose and Potentialin Education. Springer Science+Business Media, LLC,p

Butler,Yuko Goto.(2015). The use of computer games as foreign language learning tasks for digital natives,System,54,91-102

Chandler,Curtis.(2013). The Use of Game Dynamics to Enhance Curriculum and Instruction: What Teachers Can Learn from the Design of Video Games, Journal of Curriculum and Instruction (JoCl), Vol. 6, No. 2

Clark, D. B., Tanner-Smith, E. E., \& Killingsworth, S. S. (2015). Digital Games, Design, and Learning A Systematic Review and MetaAnalysis. Review of educational research, 0034654315582065.

Connolly,Thomas. (2009). Games-Based Learning Advancements for Multi-Sensory Human Computer Interfaces: Techniques and Effective Practices, Information Science Reference

Freitas, Sara de and Maharg, Paul(2010). Digital Games and Learning,London, Continuum International Publishing Group

Fullan, M. (2007). The New Meaning of Educational Change (4th ed.). New York: Teachers College Press.

Jason Fritts .(2009). Computer \& Video Game Genres CSCI 130 -Computer Game Design. Available in: http://bestcommunionideas. com/en/jason-fritts-computer-video-game-genres/

Kapp,Karl M.(2012). The Gamification of Learning and Instruction: Game-Based Methods and Strategies for Training and Education,San Francisco, Pfeiffer

Kelle, S., Klemke, R., \& Specht. M. (2013). Effects of Game Design Patterns on Basic Life Support Training Content. Educational Technology \& Society, 16 (1), 275-285

Kirriemuir, J., \& McFarlane, A. (2004). Literature review in games and learning. Retrieved from the Futurelabs Web site http://archive.futurelab.org.uk/resources/publications-reports-articles/literature-reviews/Literature-Review378

Lacasa,Pilar,Ruth,Maria,Pernia,Garcia,Nunez,Patricia.(2014). Adolescents Media Experiences in the Classroom: SimCity as a Cultural Model, Journal of Education and Training Studies, Vol. 2, No. 1

Larsen Katie McClarty.(2012).A Literature Review of Gaming in Education, available in: http://researchnetwork.pearson.com/ wpcontent/uploads/Lit_Review_of_Gaming_in_Education.pdf

Mark Mc Mahon.(2009) .The DODDEL Model: A Flexible Document-Oriented Model for the Design of Serious Games, in Thomas Connolly (Eds). Games-Based Learning Advancements for Multi-Sensory Human Computer Interfaces: Techniques and Effective Practices , Information Science Reference

Merrill, David M.(1983). Component display theory, In Reigeluth, C.M. (Eds), Instructional Design Theories and Models,(Volume I).London, Routledge.

Prensky, M. (2000). Digital game-based learning. New York: McGraw-Hill

Prensky, M. (2005). "Engage me or Enrage me"What today's learners demand. EDUCAUSE Review, 40(5), 60-65.

Shute, V. J., Ventura, M., Bauer, M. I., \& Zapata-Rivera, D. (2009). Melding the power of serious games and embedded assessment to monitor and foster learning: Flow and grow. In U. Ritterfeld, M. Cody, \& P. Vorderer (Eds.), Serious games: Mechanisms and effects (pp. 295-321). Mahwah, NJ: Routledge, Taylor and Francis.

Van Eck Richard. (2010). Interdisciplinary Models and Tools for Serious Games: Emerging Concepts and Future Directions, New York, Information Science Reference.

Van Eck, R. (2006). Digital game-based learning: It's not just the digital natives who are restless. EDUCAUSE Review, 41(2), 16-30

Whitton, Nicola.(2010). Learning with Digital Games A Practical Guide to Engaging Students in Higher Education, New York, Routledge. 